\title{
Antinociceptive and Anti-Inflammatory Effects of Total Alkaloid Extract from Fumaria capreolata
}

\author{
Noureddine Bribi, ${ }^{1,2}$ Francesca Algieri, ${ }^{1}$ Alba Rodriguez-Nogales, ${ }^{1}$ \\ Jose Garrido-Mesa, ${ }^{1}$ Teresa Vezza, ${ }^{1}$ Fadila Maiza, ${ }^{2}$ Maria Pilar Utrilla, ${ }^{1}$ \\ Maria Elena Rodriguez-Cabezas, ${ }^{1}$ and Julio Galvez ${ }^{1}$ \\ ${ }^{1}$ CIBER-EHD, Department of Pharmacology, ibs. GRANADA, Center for Biomedical Research (CIBM), University of Granada, \\ Avenida del Conocimiento, S/N, Armilla, 18100 Granada, Spain \\ ${ }^{2}$ Laboratory of Plant Biotechnology and Ethnobotany, Faculty of Natural Sciences and Life, University of Bejaia, 06000 Bejaia, Algeria
}

Correspondence should be addressed to Julio Galvez; jgalvez@ugr.es

Received 29 April 2015; Revised 3 August 2015; Accepted 4 August 2015

Academic Editor: Hajime Nakae

Copyright (C) 2015 Noureddine Bribi et al. This is an open access article distributed under the Creative Commons Attribution License, which permits unrestricted use, distribution, and reproduction in any medium, provided the original work is properly cited.

\begin{abstract}
Fumaria capreolata is used in traditional medicine in North Africa for its gastrointestinal and anti-inflammatory activities. The present study investigates the effects of total alkaloids extracted from the aerial parts of Fumaria capreolata (AFC) on LPS-induced production of proinflammatory mediators (IL-6, IL-1 $\beta$, iNOS, TNF- $\alpha$, COX-2, and MIP-2) in RAW264.7 cells. AFC significantly reduced the inflammatory response inhibiting the production of nitric oxide (NO) and IL-6 in a dose-dependent manner, without affecting the viability of cells, and downregulated mRNA expression of proinflammatory key players: IL-6, IL- $1 \beta$, iNOS, TNF- $\alpha$, and COX-2. AFC antinociceptive and anti-inflammatory properties were also evaluated on the acetic acid- and formalin-induced pain models in mice. AFC oral administration significantly inhibited acetic acid-induced writhes and reduced formalin-induced paw licking time. Therefore, AFC may be a potential candidate for the treatment of inflammatory diseases, such as colitis and arthritis.
\end{abstract}

\section{Introduction}

Acute inflammation is characterized by heat, redness, pain, and swelling and is a host response to potential harmful agents, including invading pathogens. In the long term, this response can cause progressive tissue damage, which can be the basis of different chronic conditions such as rheumatoid arthritis, asthma, or inflammatory bowel disease. Different mediators have been reported to play a key role in the pathogenesis of these inflammatory disorders, including reactive oxygen and nitrogen metabolites, eicosanoids, or cytokines such as tumor necrosis factvor- (TNF-) $\alpha$, interleukin- (IL-) $1 \beta$, and IL-6, among many others. Therefore, they are important targets for anti-inflammatory molecules [1, 2]. Currently, there are different drugs with reputed efficacy as anti-inflammatory and analgesic; however, and unfortunately, they are not suitable for all patients, particularly those with chronic pain due to limitations of potency, side effects, and lack of tolerability, hence justifying the nonstop search for alternatives [3]. We can find safe anti-inflammatory remedies among medicinal plants, which have been used since ancient times. The beneficial effects of these herbal remedies can be attributed to their content in active compounds with different chemical structure. Among them, alkaloids are one of the largest groups, also with a great chemical diversity. In fact, plants are estimated to produce approximately 12,000 different alkaloids with a wide range of pharmacological properties $[4,5]$.

The genus Fumaria consists of 46 species in the world. Some of them are known by the English terms "fumitory, earth smoke, beggary, fumus, vapor, fumitory, or wax dolls." Twenty-two of these species are restricted to the IberoMauritanian Region, which includes Algeria, Morocco, and Spain, and many are known to display biological activities $[6,7]$. Thus, their use in traditional medicine as antihypertensives and diuretics or to treat different gastrointestinal 
disorders, including constipation or functional diseases of the biliary system, has been reported. These plants have been characterized by the presence of various types of isoquinoline alkaloids in their composition, particularly aporphine, protoberberine, protopine, and benzophenanthridine [8]. In a previous study, it was reported that the total alkaloid fraction from Fumaria capreolata exerted antioxidant activity, without any toxicity in vivo, since doses up to $2,000 \mathrm{mg} / \mathrm{kg}$ did not cause any acute adverse effect when administered orally to mice [9]. The aim of this study was to further characterize the biological activities of the alkaloid fraction from Fumaria capreolata, by evaluating its anti-inflammatory properties both in vitro and in vivo.

\section{Materials and Methods}

2.1. Drugs and Chemicals. All substances were purchased from Sigma-Aldrich Chemical (St. Louis, MO, USA), unless otherwise stated. The test substances were dissolved in distilled water and prepared fresh daily for administration to the animals.

2.2. Extraction of Alkaloids. Aerial parts of Fumaria capreolata were collected from Bejaia area, in the northeast of Algeria in May 2013 when they were at the flowering and fruit setting stage. The plant was authenticated by Professor F. Benabdesselam (Laboratory of Plant Biotechnology and Ethnobotany, University of Bejaia, Algeria) and voucher specimen was deposited (reference number: FC015). The alkaloid extract of Fumaria capreolata (AFC) was obtained following the procedure previously reported [10]. Briefly, the aerial parts of the plant were dried in an oven at $40^{\circ} \mathrm{C}$ overnight and grounded into fine powder using a grinder. The powder samples $(1 \mathrm{~kg})$ were extracted with ethanol in a Soxhlet apparatus for $8 \mathrm{~h}$, evaporated under reduced pressure, acidified with $2.5 \%$ HCL to $\mathrm{pH} 1-2$ and filtered, and then stored overnight at room temperature. The aqueous acid solution was adjusted to $\mathrm{pH}=9.5$ with concentrated ammonium hydroxide and extracted with dichloromethane. The extracts were dried over magnesium sulphate and the solvent evaporated to get a crude extract of total alkaloids. After evaporation the yield of each fraction was calculated, and the alkaloid extract of Fumaria capreolata (AFC) obtained was stored at $4^{\circ} \mathrm{C}$ until use.

\section{Antinociceptive Effects of AFC}

3.1. Animals. Female albino NMRI mice (22-28g) were purchased from the Laboratory Animal Service of the University of Constantine (Algeria) and housed under standard laboratory conditions with free access to tap water and food. All behavioral tests were conducted during the light cycle and all procedures used in the present study were carried out in accordance with the current guidelines for the care of laboratory animals and the ethical guidelines for investigations of experimental inflammation and pain in conscious animals [11], following the directive number 2010/63/EU of 22 September 2010.
3.2. Acetic Acid-Induced Writhing Response. The writhing test was carried out as previously described [12]. Mice were randomly assigned to five different groups $(n=6)$, and after an overnight fasting period, they were pretreated with AFC (100, 250, or $500 \mathrm{mg} / \mathrm{kg}$, p.o.), diclofenac (100 mg/kg, p.o.), or distilled water (control group, p.o.) 60 min before the acetic acid injection (10 $\mathrm{mL} / \mathrm{kg}$ body weight, i.p.). Immediately after the injection of acetic acid, each animal was placed in a transparent plastic observation chamber. Five minutes after the administration of the acetic acid, the number of writhes and stretching movements (contraction of the abdominal musculature and extension of hind limbs) of each mouse was counted for a period of $15 \mathrm{~min}$. The percentage of inhibition of writhing was calculated and compared with the control group using the expression: inhibition $(\%)=(\mathrm{WC}-\mathrm{WT}) / \mathrm{WC} \times 100$; WC: mean of writhing (control); WT: mean of writhing (test).

3.3. Formalin-Induced Paw Licking. The formalin test was performed as previously reported $[13,14]$. Briefly, overnight fasted mice were divided into five groups $(n=5)$, which received distilled water $(10 \mathrm{~mL} / \mathrm{kg}$, p.o. $), \operatorname{AFC}(100,250$, and $500 \mathrm{mg} / \mathrm{kg}$, p.o.), or acetaminophen (100 mg/kg, p.o.) $1 \mathrm{~h}$ before formalin injection ( $20 \mu \mathrm{L}$ of $1 \%$ formalin) under the plantar surface of the right hind paw. The mice were then placed in a transparent box for observation, and the time spent licking the injected paw was measured and considered as an indication of inflammatory-associated pain. The first phase of the nociceptive response normally peaks $0-5 \mathrm{~min}$ after injection and the second phase 15-30 min after.

\section{Anti-Inflammatory Effects of AFC}

4.1. Cell Culture and Determination of Cell Viability. RAW 264.7 cells (murine macrophages) were obtained from the Cell Culture Unit of the University of Granada (Granada, Spain) and cultured in Dulbecco's Modified Eagle Medium (DMEM), supplemented with $10 \%$ FBS and $2 \mathrm{mM} 1-$ glutamine, in a humidified $5 \% \mathrm{CO}_{2}$ atmosphere at $37^{\circ} \mathrm{C}$. Cytotoxicity evaluation of the AFC was carried out in 96-well plates using the MTT assay [15]. RAW 264.7 cells were incubated in the presence of different concentrations $(12.5,25,50$, and $100 \mu \mathrm{g} / \mathrm{mL})$ of AFC and $100 \mathrm{ng} / \mathrm{mL}$ of LPS for $18 \mathrm{~h}$. The MTT solution was then added to each well and incubated for another $1 \mathrm{~h}$, when the absorbance of the solution at $490 \mathrm{~nm}$ was measured. The cellular viability was determined from the absorbance value and compared with that of the untreated control cells.

4.2. Determination of NO and IL-6 Production. RAW 264.7 cells were cultured with increasing concentrations of AFC $(12.5,25,50$, and $100 \mu \mathrm{g} / \mathrm{mL})$ and LPS $(100 \mathrm{ng} / \mathrm{mL})$. After 24 hours, the supernatants were collected. The nitrite accumulation in the supernatant was determined by the Griess assay [16]. Briefly, equal volume of cell-free culture media $(100 \mu \mathrm{L})$ was reacted with Griess reagent $(100 \mu \mathrm{L})$, and the absorbance at $540 \mathrm{~nm}$ was measured. The level of IL-6 in cell culture media was determined as well using commercial 
TABLE 1: Primer sequences used in RT-PCR assays in RAW264.7 cells.

\begin{tabular}{|c|c|c|}
\hline Gene & Primers sequences & Annealing $T\left({ }^{\circ} \mathrm{C}\right)$ \\
\hline \multirow{2}{*}{$I L-6$} & FW $5^{\prime}$-CTTCCCTACTTCACAAGTC-3' & \multirow{2}{*}{60} \\
\hline & RV 5'-CTCCATTAGGAGAGCATTG-3' & \\
\hline \multirow{2}{*}{$T N F-\alpha$} & FW 5'-AACTAGTGGTGCCAGCCGAT-3' & \multirow{2}{*}{56} \\
\hline & RV $5^{\prime}$-CTTCACAGAGCAATGACTCC- $3^{\prime}$ & \\
\hline \multirow{2}{*}{ iNOS } & FW 5'-GTTGAAGACTGAGACTCTGG-3' & \multirow{2}{*}{56} \\
\hline & RV 5'-GACTAGGCTACTCCGTGGA-3' & \\
\hline \multirow{2}{*}{$I L-1 \beta$} & FW $5^{\prime}$-TGATGAGAATGACCTCTTCT-3' & \multirow{2}{*}{55} \\
\hline & RV 5' -CTTCTTCAAAGATGAAGGAAA- $3^{\prime}$ & \\
\hline \multirow{2}{*}{$C O X-2$} & FW $5^{\prime}$-GGGTTGCTGGGGGAAGAAATG-3' & \multirow{2}{*}{67} \\
\hline & RV 5'-GGTGGCTGTTTTGGTAGGCTG-3' & \\
\hline \multirow{2}{*}{$M I P-2$} & FW 5'-CAGTTAGCCTTGCCTTTGTTCAG-3' & \multirow{2}{*}{62} \\
\hline & RV 5'-CAGTGAGCTGCGCTGTCCAATG-3' & \\
\hline \multirow{2}{*}{$G A D P H$} & FW 5'-CCATCACCATCTTCCAGGAG-3' & \multirow{2}{*}{60} \\
\hline & RV 5' -CCTGCTTCACCACCTTCTTG-3' & \\
\hline
\end{tabular}

available ELISA kits (R\&D) according to the manufacturer's instructions.

4.3. Analysis of Gene Expression by RT-PCR. RAW 264.7 cells were cultured with increasing concentrations of AFC (12.5, $25,50$, and $100 \mu \mathrm{g} / \mathrm{mL})$ for 2 hours prior to LPS $(100 \mathrm{ng} / \mathrm{mL})$ stimulation. Three hours later, cells were collected and total RNA extracted using Trizol (Ambion, Austin, TX, USA), following the manufacturer's instructions. RNA samples were quantified with the NanoDrop 2000 Spectrophotometer (Thermo Scientific, Wilmington, DE, USA), and $2 \mu \mathrm{g}$ of RNA was reverse transcribed using oligo (dT) primers (Promega, Madison, WI, USA). Real-time quantitative PCR amplification and detection were performed on optical-grade 48-well plates in an Eco Real-Time PCR System (Illumina, CA, USA) with $20 \mathrm{ng}$ of cDNA, the KAPA SYBR FAST qPCR Master Mix (KapaBiosystems, Inc., Wilmington, MA, USA), and specific primers at their annealing temperature (Table 1). To normalize mRNA expression, the expression of the housekeeping gene glyceraldehydes 3-phosphate dehydrogenase (GAPDH) was measured for comparative reference. The mRNA relative quantitation was calculated using the $\Delta \Delta \mathrm{Ct}$ method.

4.4. Statistical Analysis. All data were expressed as mean \pm standard error of the mean (SEM). The statistical analysis of all the observations was carried out using one-way ANOVA followed by multiple comparison test of Dunnett's, where necessary. A difference of $p<0.05$ was considered statistically significant compared with the negative control (untreated).

\section{Results and Discussion}

Nonsteroidal anti-inflammatory drugs (NSAIDs) are the most widely prescribed medications for the management of painful conditions associated with inflammation, but they can frequently cause gastrointestinal damage that can even lead to ulcers and hemorrhage [17]. As an alternative, plant

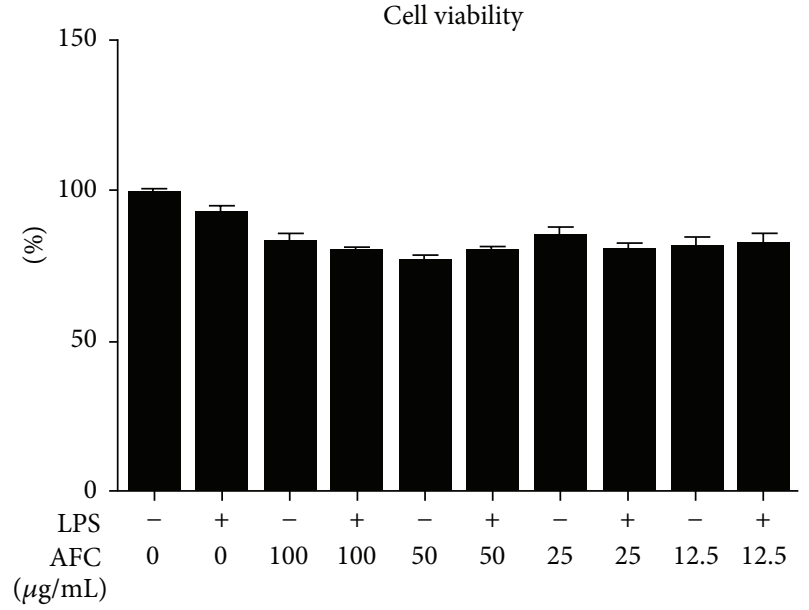

FIGURE 1: Effects of AFC on cell viability in RAW 264.7 cells treated with LPS $(100 \mathrm{ng} / \mathrm{mL})$ for $24 \mathrm{~h}$. Data are expressed as means \pm SEM $(n=6)$.

based medicines are more and more used, based on their reputed efficacy and supposed fewer adverse effects [18]. In fact, medicinal plant extracts are composed of different constituents that may exert complementary properties and mechanisms of action, thus providing synergistic effects. However, they may also result in an increased risk of harmful effects [19]. In this context, the use of more purified fractions, obtained from plant extracts that have been long used in traditional medicine, may be of special interest. In the present study, the potential anti-inflammatory effects of an alkaloid fraction from Fumaria capreolata (AFC) have been evaluated both in vitro and in vivo. With this aim, firstly we have tested AFC on LPS-stimulated macrophage activity, by using the RAW 264.7 cell line, and secondly, we have assayed the analgesic properties of AFC by using two different in vivo experimental models: acetic acid-induced writhing test and 
NO

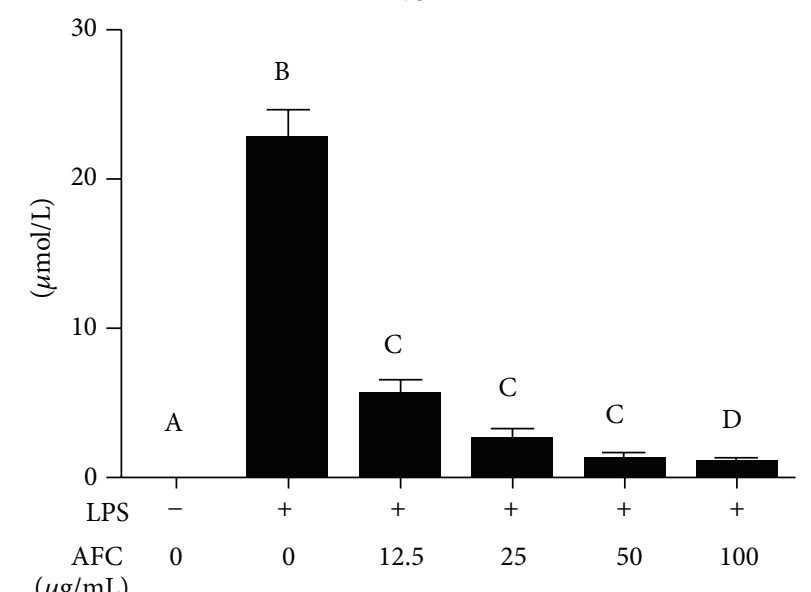

$(\mu \mathrm{g} / \mathrm{mL})$

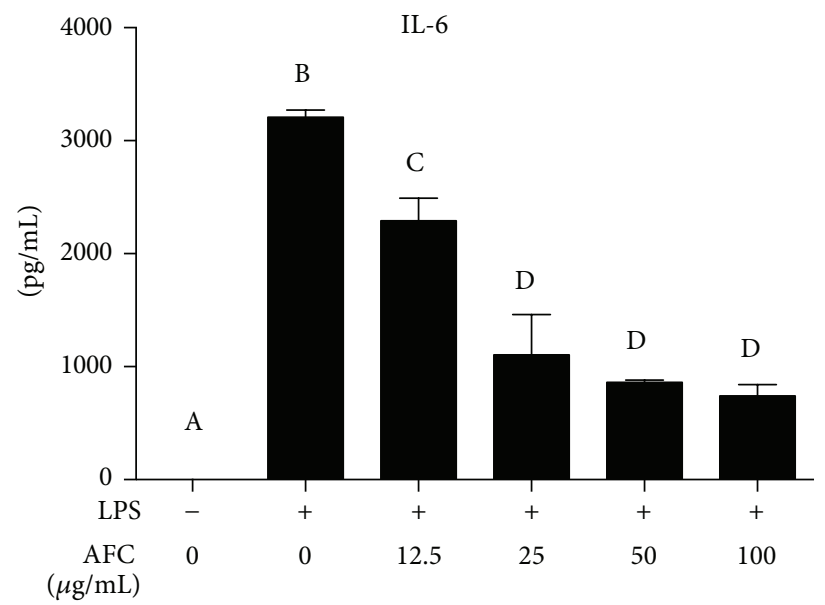

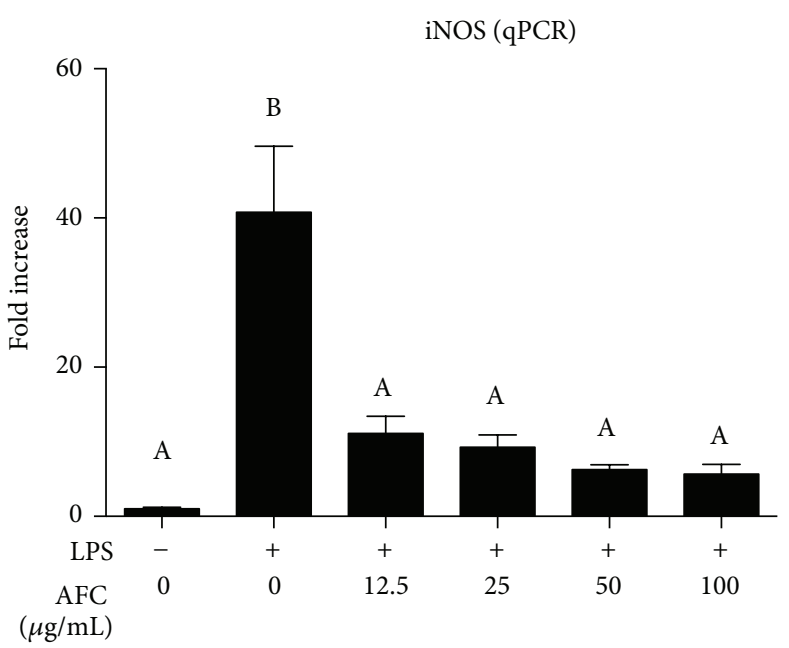

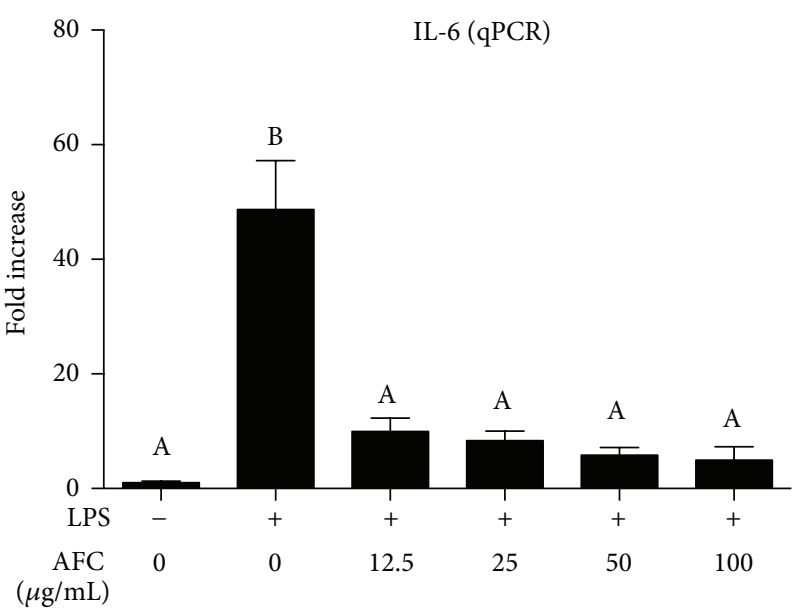

FIGURE 2: Effects of AFC on NO production (Griess reaction), iNOS expression (qPCR), IL-6 production (ELISA), and IL-6 expression (qPCR) in RAW 264.7 cells treated with LPS $(100 \mathrm{ng} / \mathrm{mL})$. Data are expressed as means \pm SEM $(n=6)$. Columns with different letter statistically differ $(p<0.05)$.

formalin-induced licking test in mice. The results obtained in the present study revealed that total alkaloid extract of aerial parts of Fumaria capreolata possessed anti-inflammatory and antinociceptive effects.

Of note, in a previous study, this alkaloid fraction was reported to show a very low toxicity when administered orally to mice [9]. The in vitro experiments performed in the present study confirmed these observations. Thus, the incubation of RAW 264.7 cells with increasing concentrations of AFC for $24 \mathrm{~h}$ revealed that the cell survival rate was greater than $75 \%$ at all concentrations assayed, and no significant differences were noted when compared with LPS treated cells (Figure 1).

Macrophages play a key role in maintaining the homeostasis of the organism and they are activated during inflammation and pathogen challenge. They experience some biochemical and morphological modifications that qualify them to perform their professional functions [20]. On the other hand, LPS is an outer membrane component of Gramnegative bacteria and a potent activator of monocytes and macrophages, through its binding to surface toll-like receptor
4 (TLR4), triggering the overexpression and subsequent secretion of a variety of inflammatory products, including TNF- $\alpha$, IL- $1 \beta$, and IL- 6 , as well as high amounts of nitric oxide (NO), which contribute to the pathophysiology of inflammatory conditions [21]. When NO production was evaluated in LPS-stimulated RAW 264.7 cells, AFC was able to significantly decrease it in a concentration dependent manner (Figure 2). Since LPS induces the expression of inducible nitric oxide synthase (iNOS) in macrophages and the synthesis of iNOS protein correlates with NO production [22], the impact of AFC on iNOS expression was also evaluated in these LPS-stimulated cells. The results revealed that this alkaloid extract significantly downregulated the increased expression of this inducible enzyme (Figure 2). Similarly, AFC inhibited dose-dependently both the production and the expression of the proinflammatory cytokine IL-6 in these macrophage cells after incubation with LPS (Figure 2). Moreover, when the mRNA expressions of other proinflammatory markers were evaluated in these cells, AFC also reduced the levels of IL- $1 \beta$, TNF- $\alpha$, and cyclooxygenase- 

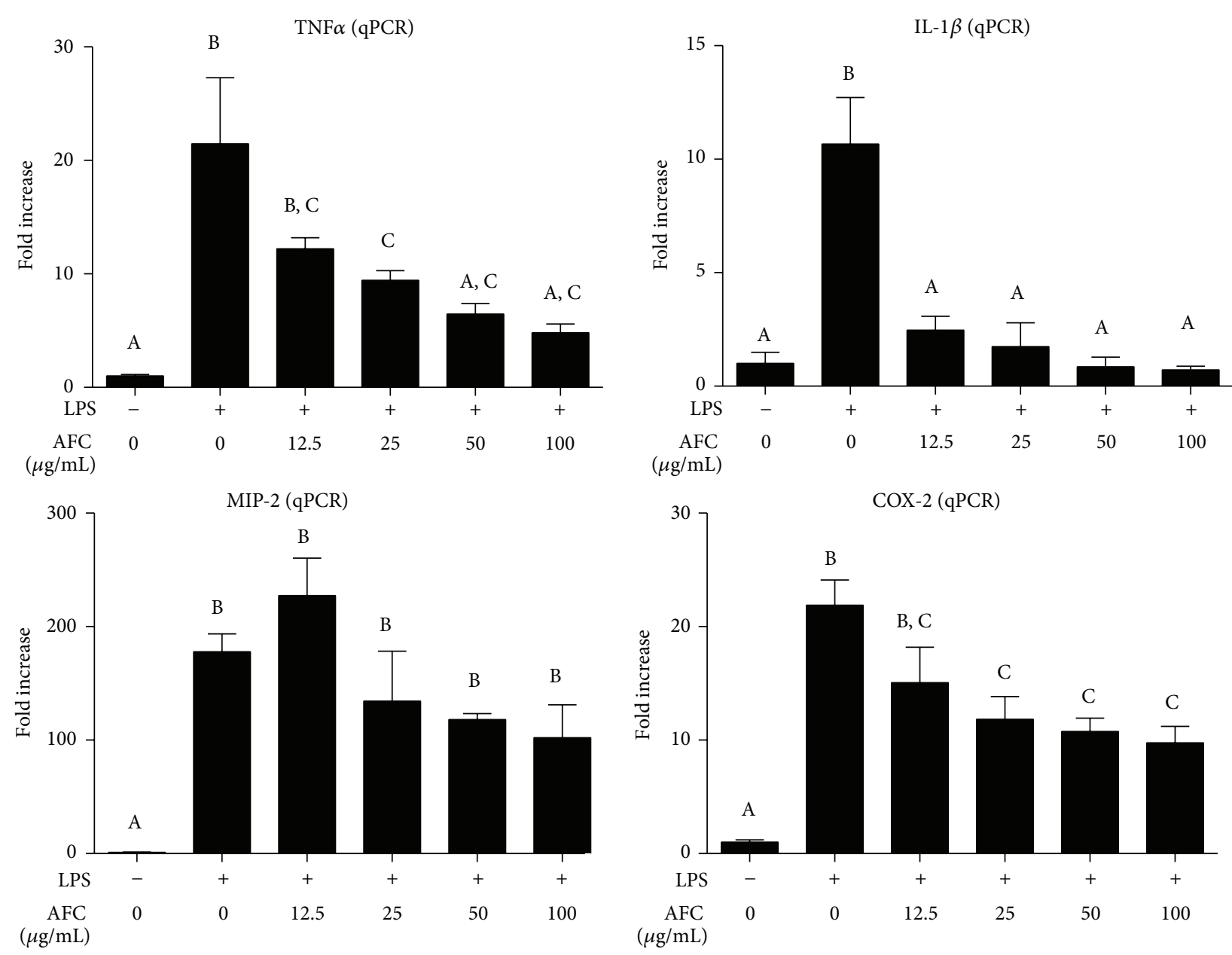

Figure 3: Effects of AFC on TNF- $\alpha$, IL-1 $\beta$, MIP-2, and COX-2 expressions determined by qPCR in RAW 264.7 cells treated with LPS $(100 \mathrm{ng} / \mathrm{mL})$. Data are expressed as means $\pm \operatorname{SEM}(n=6)$. Columns with different letter statistically differ $(p<0.05)$.

(COX-) 2 dose-dependently (Figure 3). Considering all the above, this in vitro assay may resemble a Gram-negative bacteria-mediated inflammation in macrophages, and the results obtained demonstrate that AFC was able to significantly reverse the induction of the expression of all the markers evaluated, including inducible enzymes (iNOS and COX-2) and proinflammatory cytokines (IL- $1 \beta$, TNF- $\alpha$, and IL-6). This mechanism could justify the anti-inflammatory effect for this alkaloid fraction, since the macrophages have a key role in different inflammatory conditions [23].

The writhing biting and licking response to acute nociception has been used to test the antinociceptive activity of $\mathrm{AFC}$ in mice. In the writhing test, intraperitoneal injection of $1 \%$ acetic acid evidently resulted in writhing reflex in untreated control mice. The alkaloid extract of Fumaria capreolata produced a significant inhibition of the writhing reaction induced by acetic acid when compared to the control group, this effect being dose-dependent, and with a similar efficacy at the highest dose of AFC assayed $(500 \mathrm{mg} / \mathrm{kg}$ ) to that obtained with diclofenac $(100 \mathrm{mg} / \mathrm{kg}$ ) (Figure 4(a)). It has been reported that the injection of acetic acid into the peritoneal cavity promotes an increase of cyclooxygenase and lipoxygenase products in peritoneal fluids as well as the release of many other inflammatory mediators including bradykinin and substance $\mathrm{P}$ but also proinflammatory cytokines like TNF- $\alpha$, IL-1 $\beta$, and IL- 8 which finally stimulate the primary afferent nociceptors entering the dorsal horn of the central nervous system. Acetic acid induces inflammatory pain by causing capillary permeability and liberating endogenous substances that stimulate pain nerve endings $[24,25]$. The antinociceptive activity of AFC in inflammatory conditions was confirmed after its administration to mice submitted to formalin-induced paw edema. It has been well described that, during the first phase, the injection of formalin into the subplantar tissue of the hind paw of mice produces a neurogenic nociceptive response of biting and licking of the damaged paw, which lasted in the untreated control group more than one minute. The administration of different doses of the alkaloid extract resulted in a significant reduction of the biting and licking time, thus revealing an antinociceptive potential against formalin-induced pain; although no doseresponse relationship was achieved, the efficacy obtained was 


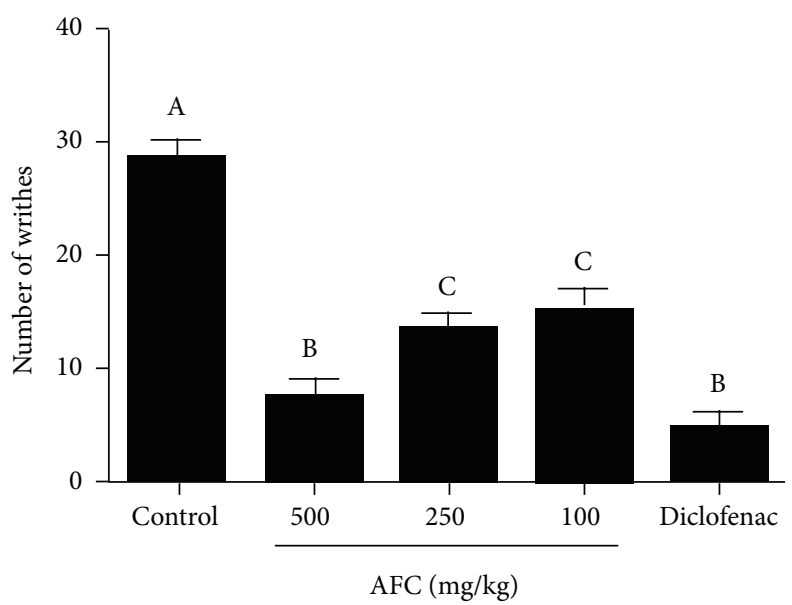

(a)
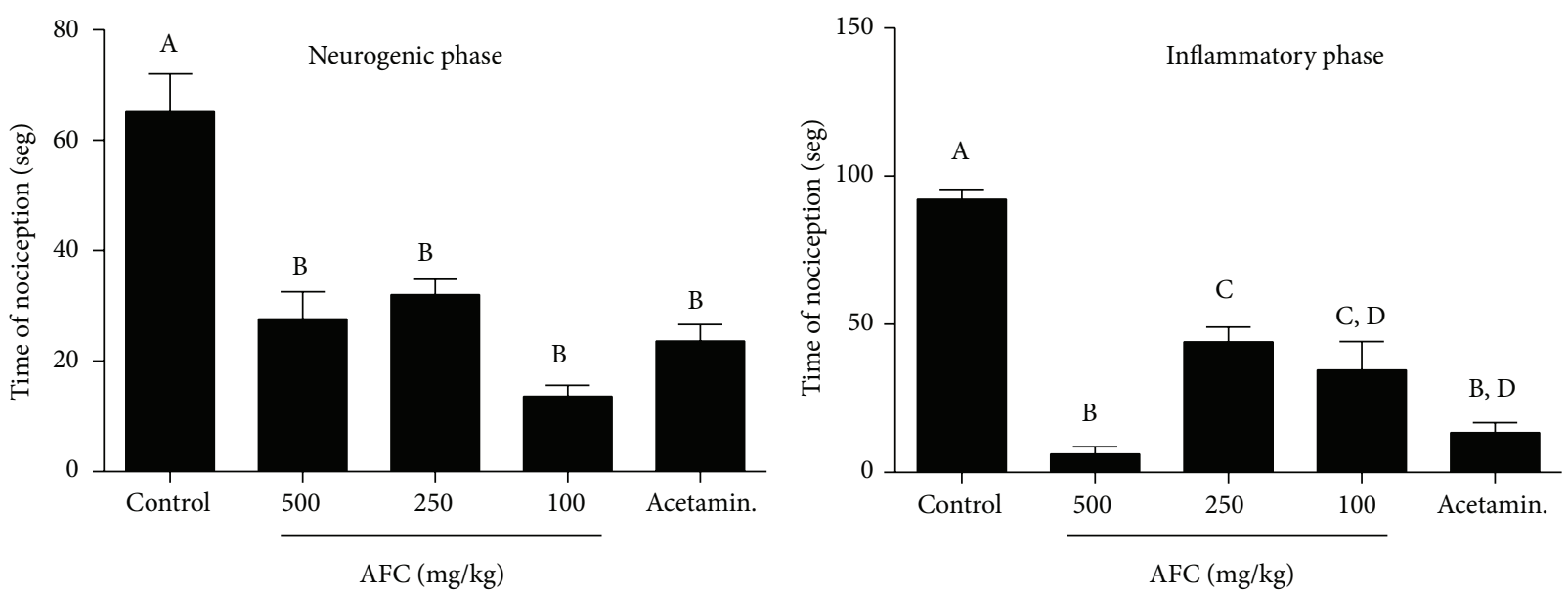

(b)

FIgURE 4: Effects of oral administration of AFC on (a) abdominal writhes induced by acetic acid in mice and (b) neurogenic phase and inflammatory phase on formalin-induced pain in mice. Data are expressed as means $\pm \operatorname{SEM}(n=6)$. Columns with different letter statistically differ $(p<0.05)$.

similar to that observed with acetaminophen, the analgesic used as positive control (Figure 4(b)). Of note, the beneficial effect exerted by AFC was maintained during the second phase of nociception that characterizes this experimental model (Figure 4(b)), which is associated with the release of inflammatory mediators that clearly contributes to the pain [14-26]. Total alkaloids of Fumaria capreolata possess antinociceptive activity against chemically induced nociception associated with inflammation. Among the different alkaloids present in the extract, protopine, an isoquinoline alkaloid, is the most medicinally active phytochemical, as it is reported to possess numerous pharmacological actions [27].

\section{Conclusion}

In conclusion, the present study suggests that total alkaloid fraction from Fumaria capreolata presents anti-inflammatory effects since it inhibits the expression and/or release of different anti-inflammatory mediators when evaluated in vitro in LPS-stimulated macrophage RAW 264.7 cells, which could contribute to its potential analgesic effect. This was supported by the results obtained in vivo, which showed that AFC significantly exerted analgesic effects in two experimental nociceptive models in which the release and/or actions of different inflammatory mediators, like vasoactive substances (histamine, serotonin, and kinins) as well as prostaglandins, play a key role.

\section{Conflict of Interests}

The authors declare that there is no conflict of interests.

\section{Acknowledgments}

This work was supported by the Spanish Ministry of Economy and Competitivity (SAF2011-29648) and Junta de Andalucia (AGR-6826 and CTS 164) with funds from the European Union; J. Garrido-Mesa is a predoctoral fellow from the 
Spanish Ministry of Education and Science; F. Algieri is a predoctoral fellow of Junta de Andalucia; M. E. RodriguezCabezas is a postdoctoral fellow of CIBER-EHD. The CIBEREHD is funded by the Instituto de Salud Carlos III. The authors would like also to thank the Ministry of Higher Education and Scientific Research, Algeria, for its support of the stay of Noureddine Bribi in Spain.

\section{References}

[1] M. Guha and N. Mackman, "LPS induction of gene expression in human monocytes," Cellular Signalling, vol. 13, no. 2, pp. 8594, 2001.

[2] T. J. Guzik, R. Korbut, and T. Adamek-Guzik, "Nitric oxide and superoxide in inflammation and immune regulation," Journal of Physiology and Pharmacology, vol. 54, no. 4, pp. 469-487, 2003.

[3] H. O. Vongtau, J. Abbah, I. E. Ngazal et al., "Anti-nociceptive and anti-inflammatory activities of the methanolic extract of Parinari polyandra stem bark in rats and mice," Journal of Ethnopharmacology, vol. 90, no. 1, pp. 115-121, 2004.

[4] C. W. Lukhoba, M. S. J. Simmonds, and A. J. Paton, "Plectranthus: a review of ethnobotanical uses," Journal of Ethnopharmacology, vol. 103, no. 1, pp. 1-24, 2006.

[5] K. A. Salminen, A. Meyer, L. Jerabkova et al., "Inhibition of human drug metabolizing cytochrome P450 enzymes by plant isoquinoline alkaloids," Phytomedicine, vol. 18, no. 6, pp. 533538, 2011.

[6] R. Suau, B. Cabezudo, R. Rico, J. M. López-Romero, and F. Nájera, "Alkaloids from Fumaria sepium and Fumaria agraria," Biochemical Systematics and Ecology, vol. 30, no. 3, pp. 263-265, 2002.

[7] I. E. Orhan, B. Şener, and S. G. Musharraf, "Antioxidant and hepatoprotective activity appraisal of four selected Fumaria species and their total phenol and flavonoid quantities," Experimental and Toxicologic Pathology, vol. 64, no. 3, pp. 205-209, 2012.

[8] R. Suau, B. Cabezudo, R. Rico, F. Nájera, and J. M. LópezRomero, "Direct determination of alkaloid contents in fumaria species by GC-MS," Phytochemical Analysis, vol. 13, no. 6, pp. 363-367, 2002.

[9] B. Noureddine, B. Yacine, and M.-B. Fadila, "Evaluation of erythrocytes toxicity and antioxidant activity of alkaloids of Fumaria capreolata," International Journal of Pharma and Bio Sciences, vol. 4, no. 2, pp. P770-P776, 2013.

[10] D. Souséeck, T. Guedon, H. Adam, E. Bocharakova, I. Taborska, and V. Valkaandmanek, "Alkaloids and organic acids content of eight Fumaria," Phytochemical Analysis, vol. 10, no. 1, pp. 6-11, 1999.

[11] M. Zimmermann, "Ethical guidelines for investigations of experimental pain in conscious animals," Pain, vol. 16, no. 2, pp. 109-110, 1983.

[12] R. Koster, M. Anderson, and E. J. De Beer, "Acetic acid for analgesic screening," Federation Proceedings, vol. 18, p. 412, 1959.

[13] S. Hunskaar and K. Hole, "The formalin test in mice: dissociation between inflammatory and non-inflammatory pain," Pain, vol. 30, no. 1, pp. 103-114, 1987.

[14] A. Tjølsen, O.-G. Berge, S. Hunskaar, J. H. Rosland, and K. Hole, "The formalin test: an evaluation of the method," Pain, vol. 51, no. 1, pp. 5-17, 1992.

[15] T. Mosmann, "Rapid colorimetric assay for cellular growth and survival: application to proliferation and cytotoxicity assays,"
Journal of Immunological Methods, vol. 65, no. 1-2, pp. 55-63, 1983.

[16] L. C. Green, D. A. Wagner, J. Glogowski, P. L. Skipper, J. S. Wishnok, and S. R. Tannenbaum, "Analysis of nitrate, nitrite, and $[15 \mathrm{~N}]$ nitrate in biological fluids," Analytical Biochemistry, vol. 126, no. 1, pp. 131-138, 1982.

[17] S. Fiorucci, E. Antonelli, and A. Morelli, "Mechanism of nonsteroidal anti-inflammatory drug-gastropathy," Digestive and Liver Disease, vol. 33, no. 2, pp. S35-S43, 2001.

[18] M. G. Dharmasiri, J. R. A. C. Jayakody, G. Galhena, S. S. P. Liyanage, and W. D. Ratnasooriya, "Anti-inflammatory and analgesic activities of mature fresh leaves of Vitex negundo," Journal of Ethnopharmacology, vol. 87, no. 2-3, pp. 199-206, 2003.

[19] A. H. Gilani and Atta-ur-Rahman, "Trends in ethnopharmacology," Journal of Ethnopharmacology, vol. 100, no. 1-2, pp. 43-49, 2005.

[20] D. A. Hume, "Differentiation and heterogeneity in the mononuclear phagocyte system," Mucosal Immunology, vol. 1, no. 6, pp. 432-441, 2008.

[21] G. F. Pinna, M. Fiorucci, J.-M. Reimund, N. Taquet, Y. Arondel, and C. D. Muller, "Celastrol inhibits pro-inflammatory cytokine secretion in Crohn's disease biopsies," Biochemical and Biophysical Research Communications, vol. 322, no. 3, pp. 778-786, 2004.

[22] J. Xaus, M. Comalada, A. F. Valledor et al., "LPS induces apoptosis in macrophages mostly through the autocrine production of TNF-alpha," Blood, vol. 95, no. 12, pp. 3823-3831, 2000.

[23] E. De Nardin, "The role of inflammatory and immunological mediators in periodontitis and cardiovascular disease," Annals of Periodontology, vol. 6, no. 1, pp. 30-40, 2001.

[24] P. P. Raj, "Pain mechanism," in Pain Medicine: A Comprehensive Review, pp. 12-23, Mosby-Year Book, St. Luis, Mo, USA, 1st edition, 1996.

[25] Y. Ikeda, A. Ueno, H. Naraba, and S. Oh-Ishi, "Involvement of vanilloid receptor VR1 and prostanoids in the acid-induced writhing responses of mice," Life Sciences, vol. 69, no. 24, pp. 2911-2919, 2001.

[26] L. K. A. M. Leal, A. A. G. Ferreira, G. A. Bezerra, F. J. A. Matos, and G. S. B. Viana, "Antinociceptive, anti-inflammatory and bronchodilator activities of Brazilian medicinal plants containing coumarin: a comparative study," Journal of Ethnopharmacology, vol. 70, no. 2, pp. 151-159, 2000.

[27] A. Rathi, A. K. Srivastava, A. Shirwaikar, A. K. Singh Rawat, and S. Mehrotra, "Hepatoprotective potential of Fumaria indica Pugsley whole plant extracts, fractions and an isolated alkaloid protopine," Phytomedicine, vol. 15, no. 6-7, pp. 470-477, 2008. 


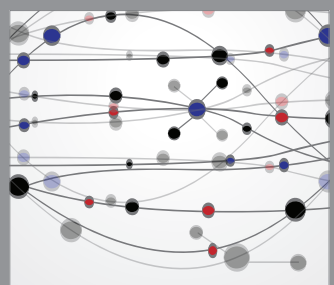

The Scientific World Journal
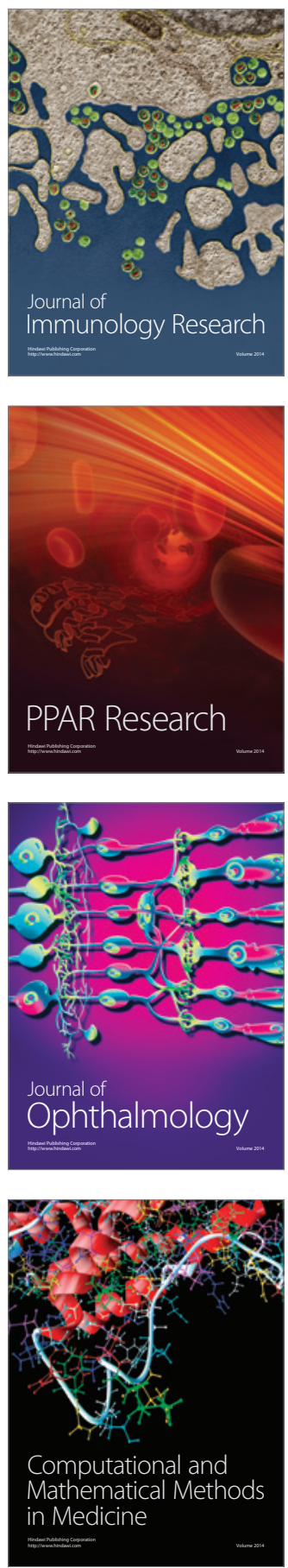

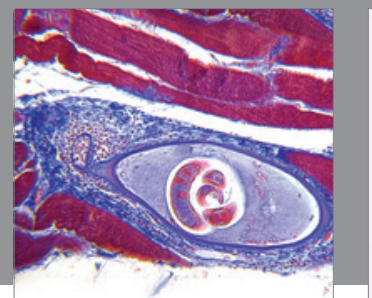

Gastroenterology

Research and Practice
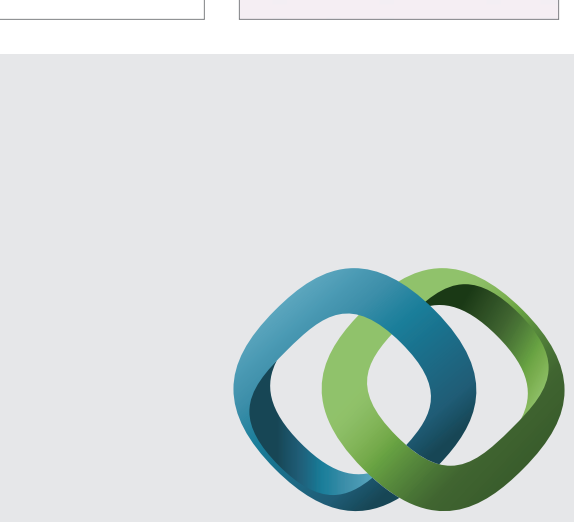

\section{Hindawi}

Submit your manuscripts at

http://www.hindawi.com
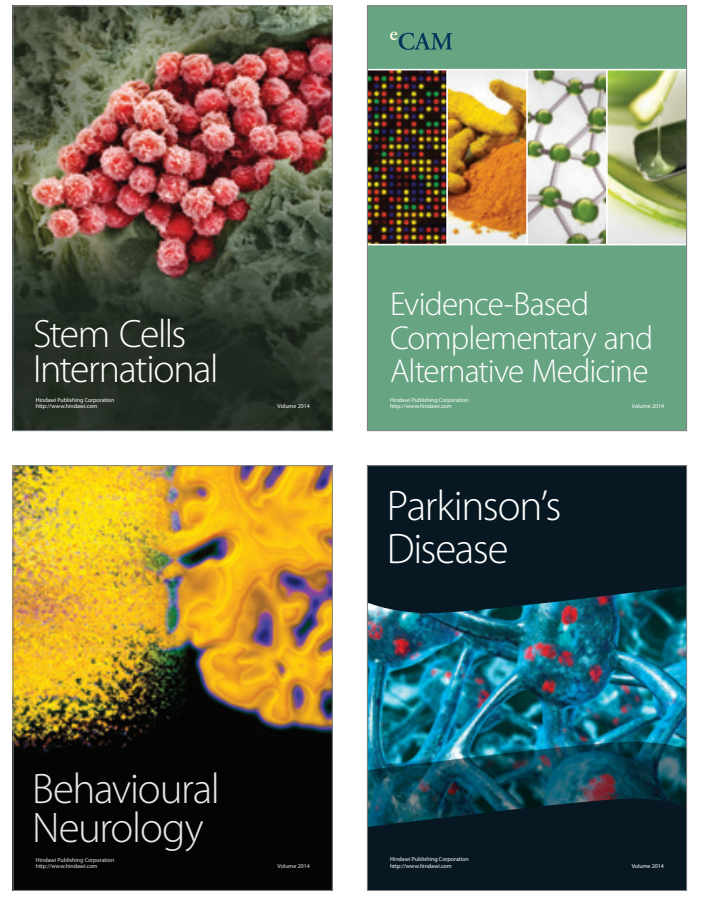
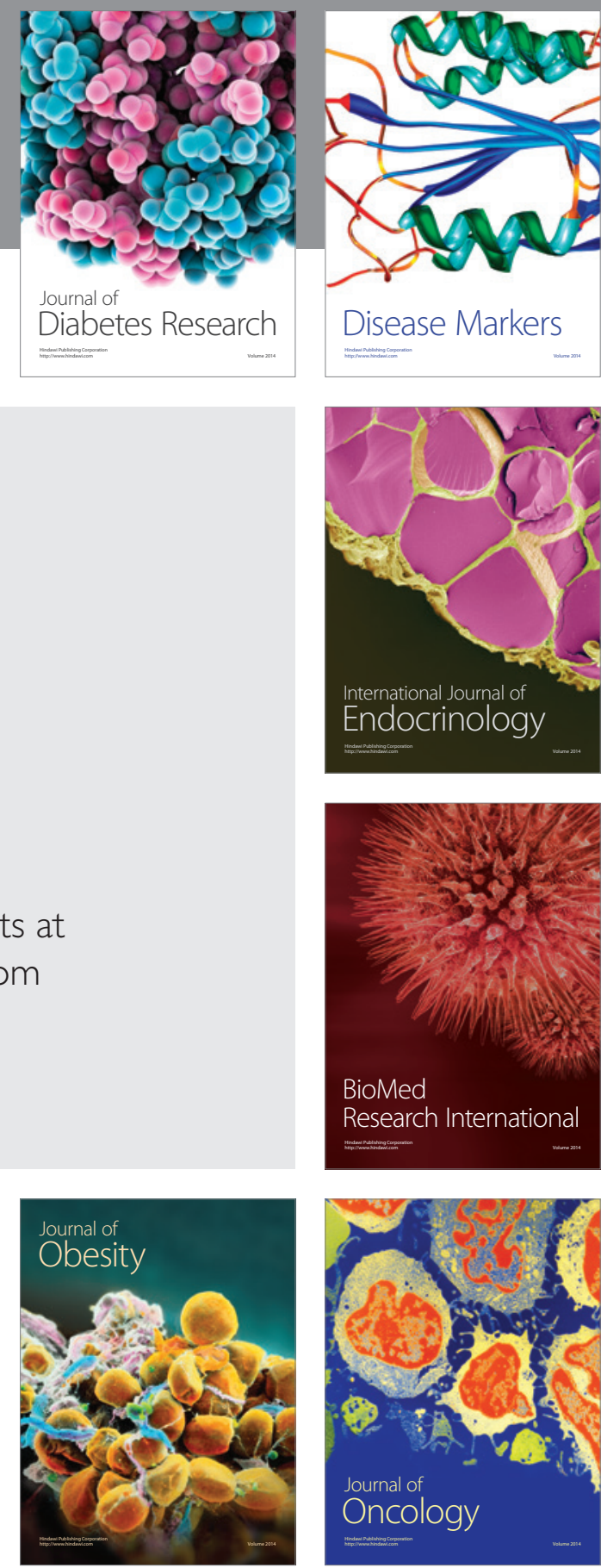

Disease Markers
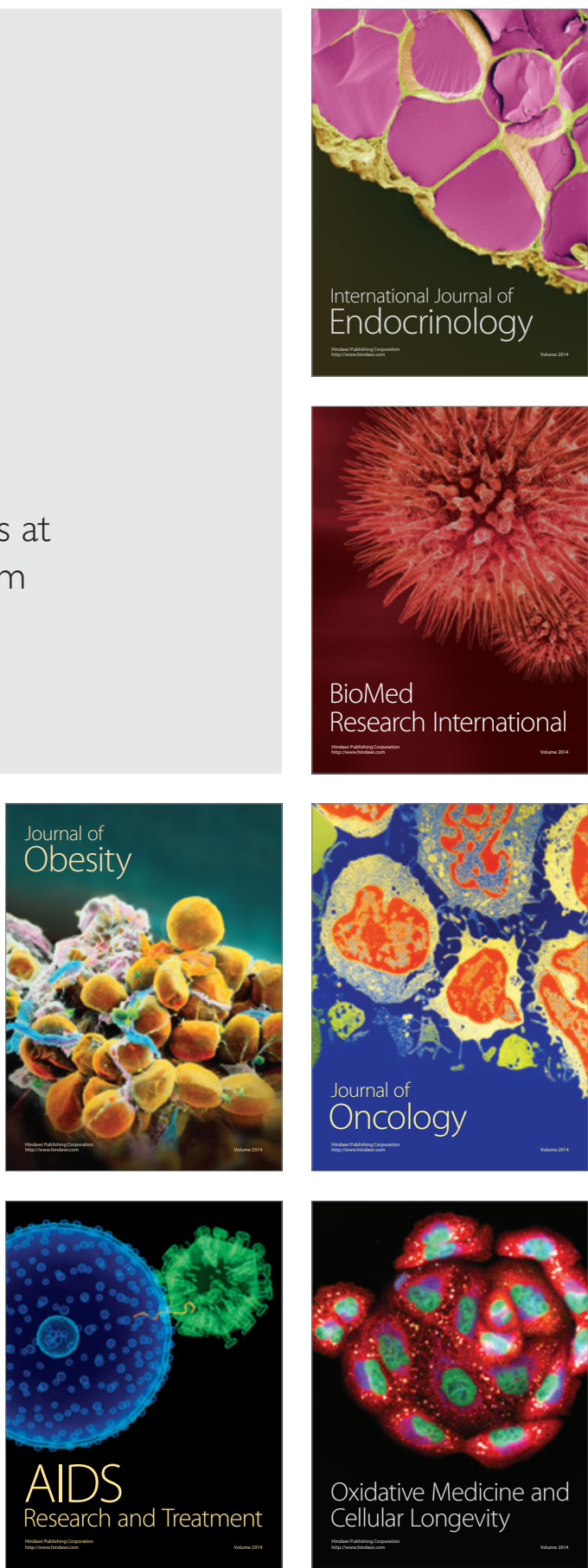